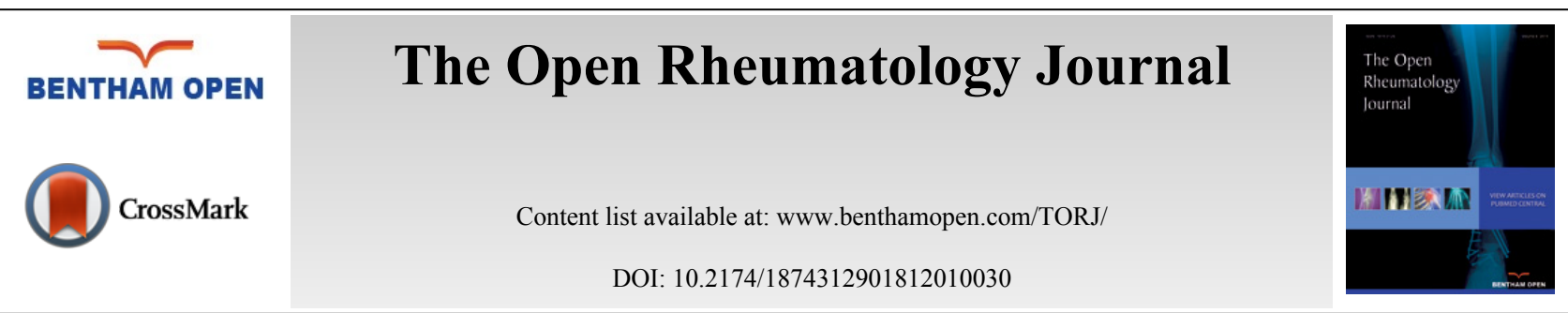

RESEARCH ARTICLE

\title{
High Secretion of Interleukin-6 and Increased MINCLE Receptor Expression Upon Exposure to Mycobacterial Cord Factor Analog Trehalose-6, 6-Dibehenate (TDB) in Patients with Takayasu Arteritis
}

Nikhil Gupta ${ }^{\#}$ Jayakanthan Kabeerdoss", Hindhumathi Mohan, Ruchika Goel and Debashish Danda $^{*}$

Department of Clinical Immunology and Rheumatology, Christian Medical College, Vellore, Tamil Nadu, India

Received: December 14, 2017

Revised: January 09, 2018

Accepted: January 25, 2018

\section{Abstract:}

\section{Introduction:}

Suspicion on the association between Takayasu Arteritis (TA) and Tubcerculosis (TB) has been in vogue for years. Prevalence of TB in TA is reported to be higher. We aimed to study innate immune responses in patients with TA on exposure to Trehalose-6,6dibehenate (TDB), a synthetic analogue of Trehalose-6,6-Dimycolate (TDM, also known as mycobacterial cord factor) in comparison with healthy controls.

\section{Materials and Methods:}

Patients with type V TA, satisfying 1990 ACR criteria, and age and sex matched healthy controls were recruited. PBMCs were cultured with $5 \mu \mathrm{g} / \mathrm{ml}, 50 \mu \mathrm{g} / \mathrm{ml}$ or without any TDB for 48 hours in RPMI medium inside a $5 \%$ Co2 incubator. IL- 6 , TNF- $\alpha$ and IL-17 were measured in cell culture supernatant, which was separated from the cells at the end of the incubation period. Gene expressions of IL-6, IL-8, TNF $\alpha$, IFN- $\gamma$, MINCLE and BCL-10 were quantified in real time PCR using specific primers and SYBR green chemistry.

\section{Results:}

Twenty two TA patients and 21 healthy controls were recruited. Both patients and controls showed response by secreting IL-6 and TNF- $\alpha$ upon stimulation by TDB. Relative induction (TDB stimulated TA sample / unstimulated control) of IL-6 was significantly higher in TA [31.88(0.74-168)] patients as compared to healthy controls [1.931(0.644-8.21); $\mathrm{p}<0.002]$, when co-cultured with $50 \mu \mathrm{g} / \mathrm{ml}$ TDB. The expression of MINCLE, the TDB receptor was higher in TA samples than healthy controls upon TDB stimulation.

\section{Conclusion:}

Stimulation with mycobacterial synthetic analogue led to higher secretion of IL-6 and higher expression of MINCLE in PBMCs of patients with TA as compared to healthy controls.

Keywords: Takayasu Arteritis, Trehalose-6, 6-dibehenate (TDB), MINCLE, Interleukin-6, Mycobacterial cord factor.

\section{INTRODUCTION}

Takayasu Arteritis (TA) is a large vessel vasculitis which predominantly affects the aorta and its main branches (1).

\footnotetext{
\# Joint first authors as equal contributors.

* Address correspondence to this author at the Department of Clinical Immunology \& Rheumatology, Christian Medical College \& Hospital, Vellore, Tamil Nadu, India, Pincode - 632004; Tel: +91-416-2282529; Fax: +91-416- 2282035; E-mail: debashisdandacmc@hotmail.com
} 
The role of micro-organisms like Mycobacterium Tuberculosis (MTB) has been proposed in the pathogenesis of TA [1, 2].

Association of TA with TB has been studied for many years, but no strong link has been established. In a cohort of 272 cases with TA, Mwipatayi et al. reported active pulmonary tuberculosis in $20 \%$ of their patients [3]. In another autopsy series of 10 TA cases, the evidence of active / healed tuberculosis at various sites was found in four of them [4]. However, studies using Tuberculin Skin Test (TST), quantiferon gamma test (QFT-G) and nucleic acid detection techniques for MTB in patients with TA could not corroborate these results [2, 5 - 7].

Patients with TA have been observed to have heightened T cell response and antibody titer to mycrobaterial $65 \mathrm{kDa}$ HSP [8, 9]. This may be due to molecular mimicry or sharing of antigenic region of HSP between humans and mycobacterium tuberculosis (9). Patients of TA and TB share common inflammatory signals which can trigger Th1 and Th17 responses and granuloma formation noted in both the scenarios [10,11].

Trehalose-6,6-dimycolate (TDM), also called as mycobacterial cord factor, is a major glycolipid present in the cell wall of mycobacterium tuberculosis. It is a potent virulence factor, which protects TB bacilli from macrophage mediated killing and inhibits effective antigen presentation [12]. Administration of TDM in mice leads to granuloma formation [13], accompanied by a cascade of pro-inflammatory cytokine production that includes TNF- $\alpha$, IL-6, IL-1 $\beta$, IFN- $\gamma$ and IL-12 as well as some chemokines [14].

Glycolipid trehalose-6,6-dibehenate (TDB), is less toxic synthetic analogue of the TDM. It evokes similar inflammatory and granulomatous response as TDM. Both TDM and TDB bind to their receptors macrophage inducible Ca2+-dependent lectin (MINCLE ;CLEC4E) and MCL (CLEC4D) leading to the induction of Th1 and Th17 immune response via Syk - Card9 - Bcl10 - Malt1 signalling pathways [15 - 17].

In this study, we revisited the link of TB with TA by studying TDB-MINCLE signalling pathways in PBMCs of Asian Indian patients with TA.

\section{PATIENTS AND METHODS}

\subsection{Participants}

Patients fulfilling 1990 American College of Rheumatology criteria for Takaysu arteritis with angiographic type V disease were recruited. Age and sex matched healthy volunteers without known history of any autoimmune disease were included as controls [7]. Patients and controls were recruited after getting informed written consent from the participants. This study was approved by the Institutional Review Board (IRB), and performed in accordance with the ethical standards laid down in the 1964 Declaration of Helsinki and its later amendments.

\subsection{Stimulation of PBMC with TDB}

PBMC was separated from blood by density gradient centrifugation using Ficoll-Paque ${ }^{\mathrm{TM}}$ Plus $(1033378$, GE Healthcare) and centrifuged at $400 \mathrm{~g}$ for $25 \mathrm{~min}$. The buffy coat obtained was taken out and washed with sterile PBS twice. PBMC was suspended in Roswell Park Memorial Institute (RPMI) 1640 medium supplemented with 10\% fetal bovine serum (Gibco, Thermo fischer ScientiifcInc, USA). PBMC of each subject was cultured at $10^{6}$ cells $/ \mathrm{ml}$ in 24 well plates (Costar, Coring NY, USA) with TDB (Invivogen, CA, USA) at concentrations of 5 and $50 \mu \mathrm{g} / \mathrm{ml}$. The previous studies on rodents and in-vitro models used concentration ranging from 5 to $50 \mathrm{ug} / \mathrm{ml}$ of TDB [11, 18]. In parallel, PBMCs cultured without the addition of TDB acted as baseline control. PBMCs were cultured for 48 hrs in $\mathrm{CO} 2$ incubator (Forma, Thermo Scientific, USA). At the end of 48 hours, the cells and supernatants were separated and stored at $-80^{\circ} \mathrm{C}$ till the gene expression study by RT-PCR was performed.

\subsection{Measurement of Cytokines}

IL-6, TNF- $\alpha$ and IL-17 were measured in supernatant by commercially available sandwich ELISA kits (R\&D systems, USA) in accordance with the manufacturer's instructions.

\subsection{Quantification of Gene Expression}

RNA was extracted from the cells using TRI reagent as per the manufacturer's recommended protocol. RNA was quantitated by nanodrop 2000 (Thermoscientific). One microgram of RNA was used for cDNA conversion using ProtoScript First Strand cDNA synthesis kit (E6300S, New England Biolabs Inc). 
Quantification of gene expression by real time PCR analysis was done in StepOnePlus ${ }^{\mathrm{TM}}$ Real-Time PCR Systems (Applied Biosystems). PCR reactions were performed using $10 \mu 1$ of $1 \mathrm{X}$ VeriQuest SYBR Green qPCR master mix (75600, USB, AffymetrixInc, USA), $0.5 \mu \mathrm{l}$ of $250 \mathrm{nM}$ of forward primer, $0.5 \mu \mathrm{l}$ of reverse primer, $2 \mu \mathrm{l}$ of five times diluted cDNA and $7 \mu \mathrm{l}$ of sterile water. The PCR conditions for individual gene expressions were optimized by gradient PCR and melting curve analysis was performed. PCR amplicons were verified by electrophoresis on $2 \%$ agarose gel, followed by visualization on a gel documentation system (AlphaImager ${ }^{\circledR}$ HP, ProteinSimple, CA, USA). We tested two housekeeping genes, Glyceraldehyde 3-phosphate Dehydrogenase (GAPDH) and human acidic ribosomal protein P0 (RPL0) for normalization of gene expression and chose RPL0 for final analysis, which has early Crossing Points (Cp) value as compared to GAPDH. All cDNA samples were then amplified for the genes of interest as well as the housekeeping gene. Table 1 depicts the list of genes studied and their primers. Cycle Threshold (Ct) or Crossing Point (Cp) values obtained from triplicate runs were analysed for quantifying target gene expression relative to the housekeeping gene using the $2-\Delta \mathrm{Cp}$ method.

Table 1. Primers used for quantitation of select gene expressions.

\begin{tabular}{|c|c|c|c|}
\hline Gene & Froward Sequence $\left(\mathbf{5}^{\prime} \rightarrow \mathbf{3}^{\prime}\right)$ & Reverse Sequence $\left(\mathbf{5}^{\prime} \rightarrow \mathbf{3}^{\prime}\right)$ & Annealing Temperature $\left({ }^{\circ} \mathbf{C}\right)$ \\
\hline$I L-6$ & CATTTGTGGTGGGTCAGG & AGTGAGGAACAAGCCAGAGC & 54 \\
\hline$I L-8$ & GAATGGGTTGCTAGAATGTGATA & CAGACTAGGGTTGCCAGATTTAAC & 52 \\
\hline$T N F-\alpha$ & CCTGCCCCAATCCCTTTATT & CCCTAAGCCCCCAATTCTCT & 52 \\
\hline$I F N-\gamma$ & TCGGTAACTGACTTGAATGTCCA & TCCTTTTCGCTTCCCTGTTTT & 54 \\
\hline$C L E C 4 E(\mathrm{Mincle})$ & CTACCGAGTCCGTGTCTACCA & CATCCAAGTGCCAGCTAAGAG & 59 \\
\hline$B C L 10$ & ATGGAGCCACGAACAACCTCT & TCGTGCTGGATTCTCCTTCTG & 56 \\
\hline$R P L P 0$ & GCTTCCTGGAGGGTGTCC & GGACTCGTTTGTACCCGTTG & 55 \\
\hline$G A P D H$ & GGTGGTCTCCTCTGACTTCAACA & AGCTTGACAAAGTGGTCGTTGAG & 58 \\
\hline
\end{tabular}

IL - interleukin, TNF - Tumour necrotic factor, IFN- interferon

\subsection{Statistical Analysis}

Cytokine levels and quantified gene expression were compared between unstimulated and TDB stimulated PBMCs using Wilcoxon signed rank test. While, unpaired t test with Welch correction or Mann Whitney test based on normality of distribution was performed for the comparisons of cytokine levels in supernatant as well as for cytokine gene expression levels between the patients with TA and healthy controls. The cytokine levels in supernatant shown in Tables ( $2 \& 3)$ are expressed as median (range). Statistical analysis was performed using Graphpad Prism software (Version 5; GraphPad Software, Inc, USA). p values less than 0.05 were considered as statistically significant.

\section{RESULTS}

Twenty two patients with TA and 21 healthy controls were recruited for study. Demographic characteristics for TA are shown in Table 4. Median age of the controls was 31 (24-45) years, and male: female ratio was 1: 3.2 .

Table 2. Clinical Details of Patients with TA.

\begin{tabular}{|c|c|}
\hline Parameter & $n=22$ \\
\hline Median age in years (range) & $27(21-32.5)$ \\
\hline Gender (Male: Female) & $4: 18$ \\
\hline Median duration of symptoms in months (range) & $8(1-60)$ \\
\hline Median age of onset in years (range) & $26.5(15-49)$ \\
\hline Median ESR in $\mathrm{mm} / 1^{\text {st }}$ hour (range) & $32(15.75-51.25)$ \\
\hline Median CRP in mg/dl (range) & $6.8(3.4-22.03)$ \\
\hline Median ITAS (range) & $7(4-14.25)$ \\
\hline Median DEI.Tak (range) & $7.5(4-13.25)$ \\
\hline Medications Used & $\mathrm{n}(\%)$ \\
\hline Treatment naïve & $14(63.64 \%)$ \\
\hline Second line Immunosuppression $((\mathrm{MMF}=6)$ and Immunomodulation $(\mathrm{MTX}=1)$ along with steroids $(\mathrm{n}=7)$ & $7(31.82 \%)$ \\
\hline Biological DMARDs & Nil \\
\hline
\end{tabular}

ESR - erythrocyte sedimentation rate, CRP- C reactive protein, ITAS - Indian Takayasu activity score, DEITAK - DISEASE EXTENT INDEX FOR TAKAYASU ARTERITIS, MMF - mycophenolate mofetil, MTX- methotrexate 
Cytokine levels in the supernatant of PBMCs cultured with or without TDB (concentration of $5 \mu \mathrm{g} / \mathrm{ml} \mathrm{and} 50 \mu \mathrm{g} / \mathrm{ml}$ ) were measured (Tables 3 and $\mathbf{4}$ respectively). There was no difference in the baseline secretion of cytokines in controls and cases. However, the relative induction (TDB stimulated/ unstimulated control) of IL-6 after stimulation with 5 and $50 \mu \mathrm{g} / \mathrm{ml}$ of TDB, was higher in cases as compared to controls. Also, the higher IL-6 induction was significant only when stimulation was done by $50 \mu \mathrm{g} / \mathrm{ml}$ of TDB (Fig. 1). IL-6 level induced by TDB was 31 (2.22-88) fold in TA patients as compared to healthy controls $[1.9(1.3-3.2)] ; \mathrm{p}<0.005$. However, there was no difference in the relative induction of TNF- $\alpha$ secretion after stimulation with both the concentrations of TDB between TA and healthy controls. IL-17 levels were undetectable in all subjects with or without TDB stimulation. IL-6 and TNF- $\alpha$ protein levels did not differ between patients currently on treatment and treatment naïve patients.

Table 3. Cytokines levels secreted by unstimulated and TDB $(5 \mu \mathrm{g} / \mathrm{ml})$ stimulated PBMCs of patients with TA and healthy controls.

\begin{tabular}{|c|c|c|c|}
\hline ELISA (pg/ml) & $\begin{array}{c}\text { Unstimulated Control } \\
\text { Median (range) }\end{array}$ & TDB Stimulated PBMC Supernatant Levels (5 $\boldsymbol{\mu g} / \mathbf{m l})$ & $\boldsymbol{p}$ Value \\
\hline IL-6_HC & $789(77.73-1834)$ & $2052(452.2-4067)$ & $<0.0001$ \\
\hline IL-6_TA & $158(41-1948)$ & $2313(554.5-7368)$ & 0.0007 \\
\hline TNF- $\alpha$ HC & $20(7.5-33.5)$ & $67(25-103)$ & $<0.0001$ \\
\hline TNF- $\alpha$ TA & $15(7.25-36.5)$ & $52.5(31.25-102)$ & 0.0037 \\
\hline
\end{tabular}

HC - healthy control, TA - Takayasu arteritis

a

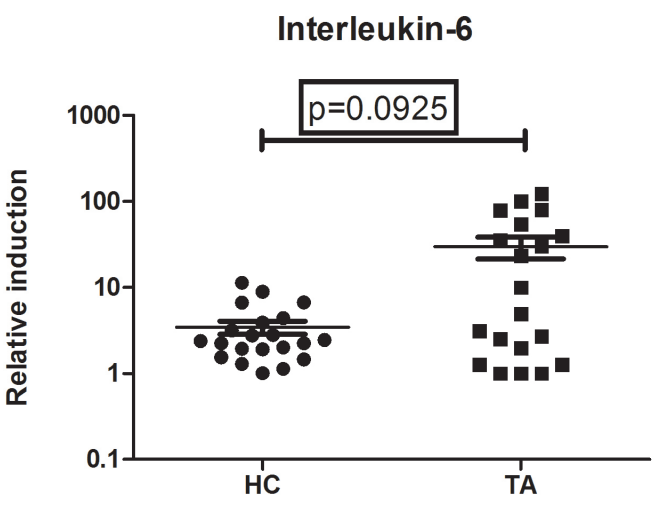

b

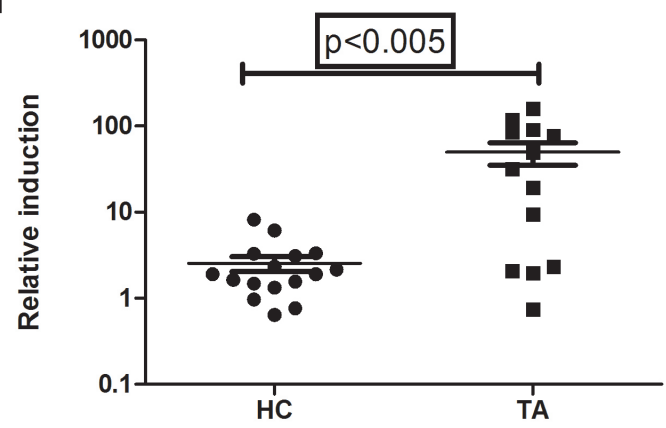

TNF- $\alpha$

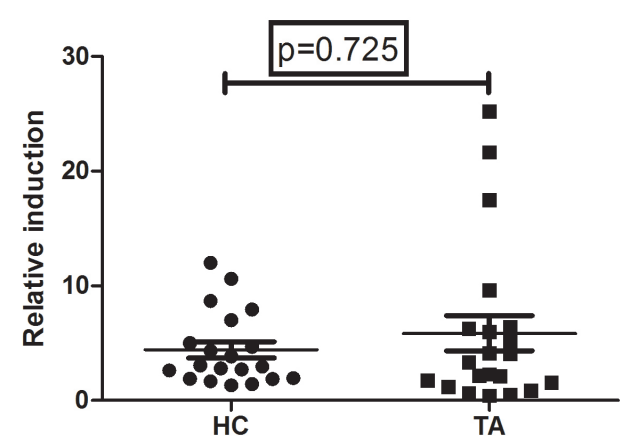

TNF- $\alpha$

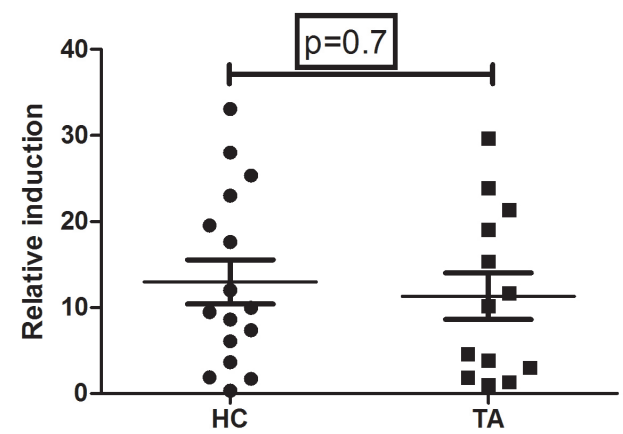

Fig. (1). Relative Induction (fold change) of IL-6 and TNF- $\alpha$ levels (a) TDB 5 (TDB5 stimulated / unstimulated baseline) depicted in the upper 2 scatterplots (b) TDB 50 (TDB50 stimulated / unstimulated baseline) depicted in the lower 2 scatterplots. Values expressed as mean \pm standard deviation. 
Table 4. Cytokines levels secreted by unstimulated and TDB $(50 \mu \mathrm{g} / \mathrm{ml})$ stimulated PBMCs of patients with TA and healthy controls.

\begin{tabular}{|c|c|c|c|}
\hline ELISA (pg/ml) & $\begin{array}{c}\text { Unstimulated Control } \\
\text { Median (range) }\end{array}$ & TDB Stimulated PBMC Supernatant Levels (50 $\boldsymbol{\mu g} /$ ml) & $\boldsymbol{p}$ Value \\
\hline IL-6 HC & $1236(246-1836)$ & $2192(613.2-3492)$ & 0.0057 \\
\hline IL-6 TA & $129.4(50.51-1100)$ & $5096(996.8-15061)$ & 0.0012 \\
\hline TNF- $\alpha$ HC & $23.5(10.25-42.25)$ & $268(35-563)$ & 0.0010 \\
\hline TNF- $\alpha$ TA & $12.5(7.25-22.75)$ & $205(33.25-463.3)$ & 0.0017 \\
\hline
\end{tabular}

MINCLE expression was significantly higher in TA as compared to healthy controls [1.03 (0.623-1.346) vs $0.43(0.36-0.57) ; p=0.0111]$ on TDB stimulation. Relative induction of gene expressions for IL-6, IL-8, TNF $\alpha$, IFN- $\gamma$ and BCL-10 after TDB stimulation was not significantly different between TA and healthy controls except MINCLE as mentioned above (Table 5).

Table 5. Relative Induction (fold change) of Gene expression by TDB50 stimulated / unstimulated baseline ratio in TA and healthy controls.

\begin{tabular}{|c|c|c|c|}
\hline Gene & HC $(\mathbf{n}=\mathbf{8})$ & TA(n=9) & p Value \\
\hline$I L-6$ & $1.03(0.58-1.45)$ & $2.1(0.77-6.76)$ & 0.1520 \\
\hline$I L-8$ & $0.87(0.47-1.87)$ & $4.72(0.82-6.791)$ & $0.071^{*}$ \\
\hline$T N F-\alpha$ & $1.21(0.69-2.11)$ & $0.95(0.86-2.023)$ & 0.9182 \\
\hline$I F N-\gamma$ & $0.98(0.8-1.616)$ & $0.96(0.35-2.31)$ & 1.000 \\
\hline$C L E C 4 E$ & $0.43(0.36-0.57)$ & $1.03(0.623-1.346)$ & $\mathbf{0 . 0 1 1 1}$ \\
\hline$B C L 10$ & $0.33(0.28-1.62)$ & $0.97(0.77-1.243)$ & 0.2991 \\
\hline
\end{tabular}

*Trend towards significance

\section{DISCUSSION}

We explored the link between tuberculosis and pathogenesis of TA by studying the recall response to mycobacterial antigen analogue TDB in PBMCs of Asian Indian patients with TA. We demonstrated that the stimulation of PBMCs with TDB led to up-regulation of its receptor MINCLE and induced increased secretion of IL-6 in cultured PBMCs of TA cases as compared to healthy controls.

The significantly increased induction of IL- 6 by TDB was observed only when the cells were stimulated at TDB concentration of 50 microgram $/ \mathrm{ml}$ and not at 5 microgram $/ \mathrm{ml}$. Previous studies on other diseases have also observed a concentration dependent inflammatory immune response to TDB stimulation [11]. The response in terms of TNF- $\alpha$ secretion also showed a similar trend, but it was not statistically significant (Table 5). This could be because of late induction of TNF-a secretion as compared to quicker secretion of IL-6 [11]. Our culture period for 48 hours in the present study may not be long enough to induce this response.

The high expression of MINCLE had been observed in PBMCs of patients with various rheumatic diseases such as rheumatoid arthritis and Bechet's disease. It has also been demonstrated in renal tissue of patients with lupus nephritis [19 - 21]. In fact, infliximab treatment in Bechet's disease results in attenuated expression of MINCLE [20]. Lipopolysaccharide and pro-inflammatory cytokines are inducers of MINCLE expression. In the present study, the basal expression of MINCLE did not differ between TA and healthy controls, but the TDB induced expression was higher as discussed above.

TDB bound to MINCLE receptor induces transcription of pro-inflammatory cytokines through Syk-Card9-Bcl10Malt1 signalling pathway [11]. However, in the present study, there was no difference in the relative expression of Bcl-10 among cases and controls. The mRNA expression of IL-6, IL-8, TNF- $\alpha$ and IFN- $\gamma$ also did not differ among cases and controls in spite of stimulation with TDB. Relative mRNA expression of IL-8 was numerically higher in TA as compared to healthy controls, but it did not reach statistical significance, though there was a trend ( $\mathrm{p}=0.071)$. IL- 8 and IL-6 are early inflammatory mediators, expressed as well as secreted by PBMCs upon TDB stimulation as early as 24 hours post stimulation and the effect lasts up to $72 \mathrm{hrs}[11,22]$. We measured gene expression at $48 \mathrm{hrs}$, by which time, most of the transcribed RNAs may have been translated to proteins; thereby, it can explain the increased level of IL-6 in culture supernatants of patients as compared to controls.

Major limitation of this study was failure to get information regarding the past exposure to TB or positive tuberculin skin test (TST) and/or Quantiferon gamma test in all study participants. Hence it is not clearly known whether the 
previous exposure to TB in TA patients resulted in quick and increased pro-inflammatory immune response by their PBMCs on re-exposure to TDB. However, the same was true for controls as well and this could have nullified that cofounding effect to a large extent. The direct role of TDB in pathogenesis of TA could not be established in this study; therefore, a study to explore this pathway as well as to reproduce our results is needed by other centres to conclude the link between TA and TB.

\section{CONCLUSION}

PBMCs of Asian Indian patients with TA showed higher MINCLE expression and IL-6 secretion as compared to healthy controls upon TDB stimulation.

\section{ETHICS APPROVAL AND CONSENT TO PARTICIPATE}

This study was approved by the Institutional Review Board (IRB), and performed in accordance with the ethical standards laid down in the 1964 Declaration of Helsinki and its later amendments.

\section{HUMAN AND ANIMAL RIGHTS}

No Animals were used in this research. All human research procedures followed were in accordance with the ethical standards of the committee responsible for human experimentation (institutional and national), and with the Helsinki Declaration of 1964, as revised in 2008.

\section{CONSENT FOR PUBLICATION}

Patients and controls were recruited after getting informed written consent from the participants.

\section{CONFLICT OF INTEREST}

The authors declare no conflict of interest, financial or otherwise.

\section{ACKNOWLEDGEMENTS}

Christian Medical College, Vellore fluid research grant for funding this project.

\section{REFERENCES}

[1] Arnaud L, Haroche J, Mathian A, Gorochov G, Amoura Z. Pathogenesis of Takayasu's arteritis: A 2011 update. Autoimmun Rev 2011; 11(1): $61-7$. [http://dx.doi.org/10.1016/j.autrev.2011.08.001] [PMID: 21855656]

[2] Castillo-Martínez D, Amezcua-Guerra LM. Self-reactivity against stress-induced cell molecules: The missing link between Takayasu's arteritis and tuberculosis. Med Hypotheses 2012; 78(4): 485-8.

[http://dx.doi.org/10.1016/j.mehy.2012.01.012] [PMID: 22285197]

[3] Mwipatayi BP, Jeffery PC, Beningfield SJ, et al. Takayasu arteritis: Clinical features and management: Report of 272 cases. ANZ J Surg 2005; 75(3): 110-7. [http://dx.doi.org/10.1111/j.1445-2197.2005.03312.x] [PMID: 15777385]

[4] Sharma BK, Jain S, Radotra BD. An autopsy study of Takayasu arteritis in India. Int J Cardiol 1998 [http://dx.doi.org/10.1016/S0167-5273(98)00155-7]

[5] Karadag O, Aksu K, Sahin A, et al. Assessment of latent tuberculosis infection in Takayasu arteritis with tuberculin skin test and quantiferonTB gold test. Rheumatol Int 2010; 30(11): 1483-7. [http://dx.doi.org/10.1007/s00296-010-1444-z] [PMID: 20358203]

[6] Arnaud L, Cambau E, Brocheriou I, et al. Absence of Mycobacterium tuberculosis in arterial lesions from patients with Takayasu's arteritis. J Rheumatol 2009; 36(8): 1682-5.

[http://dx.doi.org/10.3899/jrheum.080953] [PMID: 19531763]

[7] Soto ME, Del Carmen Ávila-Casado M, Huesca-Gómez C, et al. Detection of IS6110 and HupB gene sequences of Mycobacterium tuberculosis and bovis in the aortic tissue of patients with Takayasu's arteritis. BMC Infect Dis 2012; $12: 194$. [http://dx.doi.org/10.1186/1471-2334-12-194] [PMID: 22905864]

[8] Aggarwal A, Chag M, Sinha N, Naik S. Takayasu's arteritis: Role of Mycobacterium tuberculosis and its 65 kDa heat shock protein. Int J Cardiol 1996; 55(1): 49-55. [http://dx.doi.org/10.1016/0167-5273(96)02660-5] [PMID: 8839810]

[9] Kumar Chauhan S, Kumar Tripathy N, Sinha N, Singh M, Nityanand S. Cellular and humoral immune responses to mycobacterial heat shock protein-65 and its human homologue in Takayasu's arteritis. Clin Exp Immunol 2004; 138(3): 547-53. 
[http://dx.doi.org/10.1111/j.1365-2249.2004.02644.x] [PMID: 15544635]

[10] Saadoun D, Garrido M, Comarmond C, et al. Th1 and Th17 cytokines drive inflammation in Takayasu arteritis. Arthritis Rheumatol 2015; 67(5): 1353-60.

[http://dx.doi.org/10.1002/art.39037] [PMID: 25604824]

[11] Werninghaus K, Babiak A, Gross O, et al. Adjuvanticity of a synthetic cord factor analogue for subunit Mycobacterium tuberculosis vaccination requires FcRgamma-Syk-Card9-dependent innate immune activation. J Exp Med 2009; 206(1): 89-97. [http://dx.doi.org/10.1084/jem.20081445] [PMID: 19139169]

[12] Welsh KJ, Hunter RL, Actor JK. Trehalose 6,6'-dimycolate a coat to regulate tuberculosis immunopathogenesis. Tuberculosis (Edinb) 2013; 93(Suppl.): S3-9. [http://dx.doi.org/10.1016/S1472-9792(13)70003-9] [PMID: 24388646]

[13] Ryll R, Kumazawa Y, Yano I. Immunological properties of trehalose dimycolate (cord factor) and other mycolic acid-containing glycolipids-a review. Microbiol Immunol 2001; 45(12): 801-11. [http://dx.doi.org/10.1111/j.1348-0421.2001.tb01319.x] [PMID: 11838897]

[14] Perez RL, Roman J, Roser S, et al. Cytokine message and protein expression during lung granuloma formation and resolution induced by the mycobacterial cord factor trehalose-6,6'-dimycolate. J Interferon Cytokine Res 2000; 20(9): 795-804. [http://dx.doi.org/10.1089/10799900050151067] [PMID: 11032399]

[15] Miyake Y, Toyonaga K, Mori D, et al. C-type lectin MCL is an FcR $\gamma$-coupled receptor that mediates the adjuvanticity of mycobacterial cord factor. Immunity 2013; 38(5): 1050-62. [http://dx.doi.org/10.1016/j.immuni.2013.03.010] [PMID: 23602766]

[16] Ishikawa E, Ishikawa T, Morita YS, et al. Direct recognition of the mycobacterial glycolipid, trehalose dimycolate, by C-type lectin Mincle. J Exp Med 2009; 206(13): 2879-88

[http://dx.doi.org/10.1084/jem.20091750] [PMID: 20008526]

[17] Davidsen J, Rosenkrands I, Christensen D, et al. Characterization of cationic liposomes based on dimethyldioctadecylammonium and synthetic cord factor from M. tuberculosis (trehalose 6,6'-dibehenate)-a novel adjuvant inducing both strong CMI and antibody responses. Biochim Biophys Acta 2005; 1718(1-2): 22-31.

[http://dx.doi.org/10.1016/j.bbamem.2005.10.011] [PMID: 16321607]

[18] Schoenen H, Bodendorfer B, Hitchens K, et al. Cutting edge: Mincle is essential for recognition and adjuvanticity of the mycobacterial cord factor and its synthetic analog trehalose-dibehenate. J Immunol Baltim Md 1950; 184(6): 2756-60.

[19] Nakamura N, Shimaoka Y, Tougan T, et al. Isolation and expression profiling of genes upregulated in bone marrow-derived mononuclear cells of rheumatoid arthritis patients. DNA Res Int J Rapid Publ Rep Genes Genomes 2006; 13(4): 169-83. [http://dx.doi.org/10.1093/dnares/ds1006]

[20] Keino H, Watanabe T, Taki W, Okada AA. Effect of infliximab on gene expression profiling in Behcet's disease. Invest Ophthalmol Vis Sci 2011; 52(10): 7681-6 [http://dx.doi.org/10.1167/iovs.11-7999] [PMID: 21862654]

[21] Thiyagarajan D, Fismen S, Seredkina N, et al. Silencing of renal DNaseI in murine lupus nephritis imposes exposure of large chromatin fragments and activation of Toll like receptors and the Clec4e. PLoS One 2012; 7(3): e34080. [http://dx.doi.org/10.1371/journal.pone.0034080] [PMID: 22479529]

[22] Ostrop J, Jozefowski K, Zimmermann S, et al. Contribution of MINCLE-SYK Signaling to activation of Primary Human APCs by mycobacterial cord factor and the Novel Adjuvant TDB. J Immunol Baltim Md 1950; 195(5): 2417-28.

\section{(C) 2018 Gupta et al.}

This is an open access article distributed under the terms of the Creative Commons Attribution 4.0 International Public License (CC-BY 4.0), a copy of which is available at: (https://creativecommons.org/licenses/by/4.0/legalcode). This license permits unrestricted use, distribution, and reproduction in any medium, provided the original author and source are credited. 